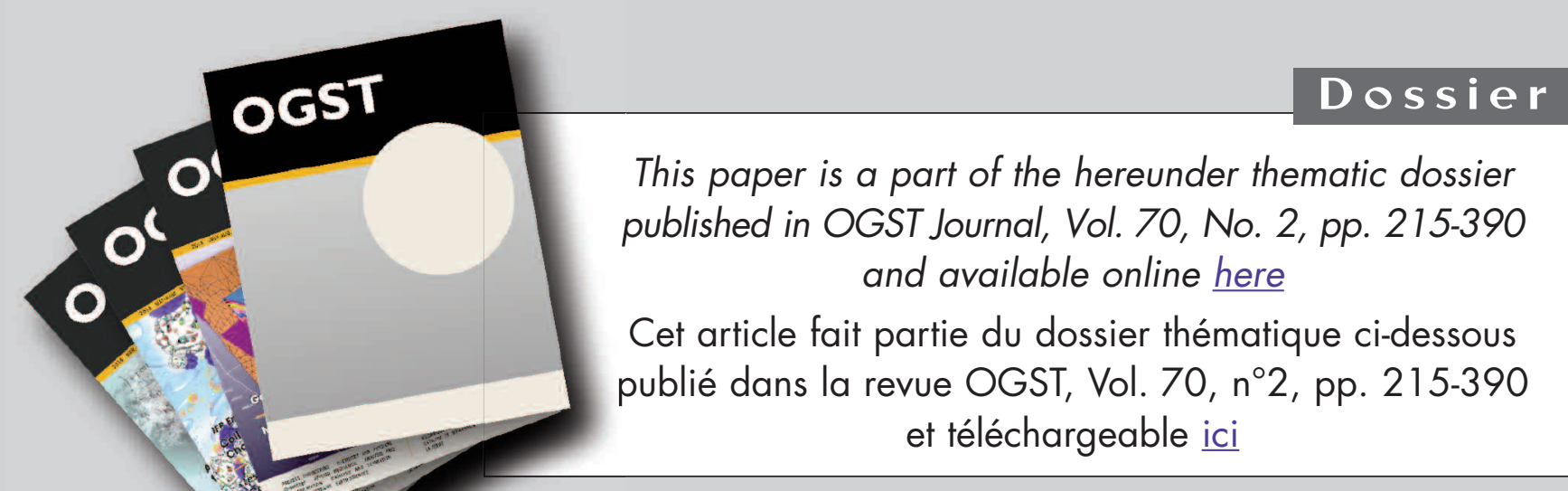

DOSSIER Edited by/Sous la direction de : B. Dewimille

Fluids-Polymers Interactions: Permeability, Durability

Interactions fluides polymères : perméabilité, durabilité

Oil \& Gas Science and Technology - Rev. IFP Energies nouvelles, Vol. 70 (2015), No. 2, pp. 215-390

Copyright (C) 2015, IFP Energies nouvelles

$215>$ Tribute to Yves Chauvin Hommage à Yves Chauvin

S. Candel and 0 . Appert

$219>$ Editorial

G. Kimmerlin

227 > Gas Permeation in Semicrystalline Polyethylene as Studied by Molecular Simulation and Elastic Model

Perméation de gaz dans le polyéthylène semi-cristallin par simulation moléculaire et modèle élastique

P. Memari, V. Lachet and B. Rousseau

237 > Reinforcement of the Gas Barrier Properties of Polyethylene and Polyamide Through the Nanocomposite Approach: Key Factors and Limitations

Renforcement des propriétés barrière aux gaz de matrices polyéthylène et polyamide par l'approche nanocomposite : facteurs clés et limitations E. Picard, J.-F. Gérard and É. Espuche

251 > Diffuso-Kinetics and Diffuso-Mechanics of Carbon Dioxide / Polyvinylidene Fluoride System under Explosive Gas Decompression: Identification of Key Diffuso-Elastic Couplings by Numerical and Experimental Confrontation

Cinétique de diffusion et comportement diffuso-mécanique du système dioxide de carbone / polyfluorure de vinylidène sous décompression explosive de gaz : identification des couplages diffuso-élastiques majeurs par confrontation numérique et expérimentale

J.-C. Grandidier, C. Baudet, S. A. E. Boyer, M.-H. Klopffer and L. Cangémi

267 > Characterization of Polymer Layered Silicate Nanocomposites by Rheology and Permeability Methods: Impact of the Interface Quality

Caractérisation de nanocomposites polymère silicate par des méthodes de rhéologie et de perméabilité : rôle de la qualité de l'interface

R. Waché, M.-H. Klopffer and S. Gonzalez

$279>$ Evaluation of Long Term Behaviour of Polymers for Offshore Oil and Gas Applications

Durabilité des polymères pour application pétrolière offshore

P.-Y. Le Gac, P. Davies and D. Choqueuse

$291>$ Development of Reactive Barrier Polymers against Corrosion for the Oil and Gas Industry: From Formulation to Qualification through the Development of Predictive Multiphysics Modeling

Développement de matériaux barrières réactifs contre la corrosion pour l'industrie pétrolière : de la formulation à la qualification industrielle en passant par le développement de modèles multiphysiques prédictifs

X. Lefebvre, D. Pasquier, S. Gonzalez, T. Epsztein, M. Chirat and F. Demanze
$305>$ Development of Innovating Materials for Distributing Mixtures of Hydrogen and Natural Gas. Study of the Barrier Properties and Durability of Polymer Pipes

Développement de nouveaux matériaux pour la distribution de mélanges de gaz naturel et d'hydrogène. Étude des propriétés barrière et de la durabilité de tubes polymères

M.-H. Klopffer, P. Berne and É. Espuche

317 > New Insights in Polymer-Biofuels Interaction

Avancées dans la compréhension des interactions polymères-biocarburants E. Richaud, F. Diouani, B. Fayolle, J. Verdu and B. Flaconneche

$335>$ Biofuels Barrier Properties of Polyamide 6 and High Density Polyethylene Propriétés barrière aux bio essences du polyamide 6 (PA6) et du polyéthylène haute densité (PEHD)

L.-A. Fillot, S. Ghiringhelli, C. Prebet and S. Rossi

353 > Permeability of EVOH Barrier Material used in Automotive Applications: Metrology Development for Model Fuel Mixtures

Perméabilité d'un matériau barrière EVOH utilisé dans des applications automobiles : développement métrologique pour des mélanges modèles de carburants

J. Zhao, C. Kanaan, R. Clément, B. Brulé, H. Lenda and A. Jonquières

367 > Effects of Thermal Treatment and Physical Aging on the Gas Transport Properties in Matrimid ${ }^{\circledR}$

Les effets du traitement thermique et du vieillissement physique sur les caractéristiques du transport au gaz dans le Matrimid ${ }^{\circledR}$

L. Ansaloni, M. Minelli, M. Giacinti Baschetti and G. C. Sarti

381 > Separation of Binary Mixtures of Propylene and Propane by Facilitated Transport through Silver Incorporated Poly(Ether-Block-Amide) Membranes Séparation de mélanges binaires de propylène et de propane par transport au travers des membranes de poly(éther-blocamide) incorporant de l'argent R. Surya Murali, K. Yamuna Rani, T. Sankarshana, A. F. Ismail and S. Sridhar 


\title{
Reinforcement of the Gas Barrier Properties of Polyethylene and Polyamide Through the Nanocomposite Approach: Key Factors and Limitations
}

\author{
E. Picard ${ }^{1,2}$, J.-F. Gérard ${ }^{1,3}$ and E. Espuche ${ }^{1,2 *}$ \\ ${ }^{1}$ Université de Lyon, 69003 Lyon - France \\ ${ }^{2}$ CNRS, UMR5223, Ingénierie des Matériaux Polymères, Université Lyon 1, 69622 Villeurbanne - France \\ ${ }^{3}$ CNRS, UMR5223, Ingénierie des Matériaux Polymères, INSA Lyon 1, 69621 Villeurbanne - France \\ e-mail: eliane.espuche@univ-lyon 1.fr \\ * Corresponding author
}

\begin{abstract}
Résumé - Renforcement des propriétés barrière aux gaz de matrices polyéthylène et polyamide par l'approche nanocomposite : facteurs clés et limitations - Dans cette étude, des nanocomposites sont préparés par voie fondue pour deux matrices, une matrice polyamide 6 (PA6) et une matrice polyéthylène (PE), leur morphologie ainsi que leurs propriétés barrières sont étudiées. Les argiles organophiles sont choisies en fonction de la nature chimique de chacune des matrices polymères. Les nanocomposites préparés à partir de polyamide 6 présentent une structure exfoliée et des propriétés barrières améliorées alors qu'une morphologie de type microcomposite ne conduisant à aucune amélioration des propriétés barrières est obtenue pour le système $\mathrm{PE} /$ montmorillonite. Différents polyéthylènes modifiés sont alors évalués en tant qu'agents compatibilisants pour les systèmes PE. Les effets de la masse molaire, de la polarité et de la fraction massique d'agent compatibilisant sur la dispersion des charges et sur les propriétés barrières sont étudiés. Un taux massique d'agent compatibilisant égal à 4 fois celui des charges s'avère être optimal pour l'ensemble des agents compatibilisants. Par ailleurs, la masse molaire des agents compatibilisants joue un rôle primordial sur l'état de dispersion des charges. Contrairement aux systèmes PA, les propriétés barrières des systèmes $\mathrm{PE}$ ne sont pas directement reliées à l'état de dispersion des charges mais dépendent également des interfaces charges/matrice. Les PE oxydés de faible masse molaire sont identifiés comme des agents compatibilisants particulièrement intéressants pour les propriétés barrières et une optimisation pas à pas des systèmes est entreprise. Une combinaison de PE oxydé de faible masse molaire et de PE greffé anhydride maléique de haute masse molaire conduisant à diviser la perméabilité aux gaz du nanocomposite d'un facteur 2 par rapport à la matrice PE s'avère particulièrement intéressante.
\end{abstract}

\section{Abstract - Reinforcement of the Gas Barrier Properties of Polyethylene and Polyamide Through the Nanocomposite Approach: Key Factors and Limitations - In this study, polyamide 6 ( PA6) and polyethylene $(P E)$ nanocomposites were prepared from melt blending and a detailed characterization of the nanocomposite morphology and gas barrier properties was performed. The choice of the organo- clay was adapted to each polymer matrix. Exfoliated morphology and improved gas transport}

This is an Open Access article distributed under the terms of the Creative Commons Attribution License (http://creativecommons.org/licenses/by/4.0), which permits unrestricted use, distribution, and reproduction in any medium, provided the original work is properly cited. 


\begin{abstract}
properties were obtained by melt mixing the polar PA6 matrix and the organoclay, whereas a microcomposite with poor barrier properties was formed from the binary PE/organomodified clay mixture. Different modified polyethylenes were examined as compatibilizers for the polyethylenel organoclay system. The effect of compatibilizer molar mass, polarity and content was investigated on the clay dispersion and on the gas barrier properties. The optimal compatibilizer to clay weight ratio was found to be equal to 4 whatever the compatibilizer. However, a high degree of clay delamination was obtained with the high molar mass compatibilizer whereas highly swollen clay aggregates resulted from the incorporation of the low molar mass interfacial agents. Contrary to the PA based system, the barrier properties of PE nanocomposites were not directly related to the clay dispersion state but resulted also from the matrix/clay interfacial interactions. Oxidized wax was identified as a very promising interfacial agent and a step by step study was performed to optimize the gas transport properties of the systems based on PE, oxidized wax and organoclay. In particular, an interesting combination of oxidized wax and high molar mass maleic anhydride grafted polyethylene allowing dividing the gas permeability by a factor 2 in comparison with neat PE was proposed.
\end{abstract}

\section{INTRODUCTION}

Due to their easy processing and their interesting mechanical properties, polyethylene (PE) and polyamide (PA) are of major interest for industrial applications going from structural applications to more specific domains such as packaging, fuel tank or gas distribution. Polyamide and polyethylene display opposite properties towards the diffusion of small molecules such as simple gas, water or solvents due to their totally different polarity, explaining why they are often combined in a multilayer approach [1, 2]. However, improvement of PA and PE layer properties is still required to respond to the ever increasing barrier level required by the applications.

Several strategies have been proposed to increase the gas barrier properties of polymer layers. The first technology consists in blending with a higher barrier polymeric material, which shall ideally be dispersed as elongated domains oriented perpendicular to the direction of gas flow to increase the gas diffusion pathway by a tortuosity effect. If the range of polymers that can be considered as high gas barrier materials in comparison with PE is large [3-5], it is much more restricted for PA [6-8]. Moreover, the main problems related to this approach are first, the generally low compatibility between the two polymers involved in the blends in absence of compatibilizer [1, 9, 10], resulting then in micrometer size dispersed domains and second, the need to perfectly control the orientation process applied to the sample to generate fibrillar type morphology [4, 11-13].

Addition of impermeable fillers of varying surface chemistry and aggregate size/aspect ratio has been presented as an interesting alternative to polymer blending, due to the possibility to tune the shape and size of the dispersed phase before its introduction within the polymer matrix [14-16]. A lot of attention has been particularly paid these last years on nanofillers such as clays to reinforce PA or PE properties [17-36]. Indeed due to their high aspect ratio and their impermeable character, the clay platelets are expected to induce significant tortuosity effects when they are dispersed within a polymer matrix. Different models [21, 37-42] have been proposed in the literature to express the tortuosity factor as a function of the shape, orientation, dispersion state and volume fraction of the dispersed impermeable particles. All these geometrical laws demonstrate that the barrier properties must be highly improved when the silicate platelets are individualized, uniformly dispersed within the polymer and are lying in the plane of the film. Hence much attention has been paid to obtain such morphologies, characterized by a high degree of clay exfoliation. However, the simple tortuous path model which considers the nanocomposite as an ideal binary system can not explain some experimental observations in the literature that yield either much lower [43-45] or on the contrary much higher permeability values than predicted [22, 28-30]. New conceptual approaches consisting in considering heterogeneous materials as resulting from three phases, namely the continuous phase, the dispersed phase and the interface, have progressively come to light [22, 28, 30, 43-47]. Thus the mechanisms of gas barrier reinforcement in nanocomposites can be very complex due to the numerous factors that can significantly influence these functional properties. It seems thus very important to identify their respective role to further optimize the properties.

The aim of the present study is first to evidence the influence of the polarity of the polymer continuous phase on the nanocomposite morphology and properties by comparing nanocomposite materials prepared from melt blending organoclays (OMMT) with PA matrix on one hand and PE matrix on the other hand. The second objective of this work is to distinguish, from the study of specifically chosen and prepared nanocomposites, 
TABLE 1

Main characteristics of the materials used to prepare nanocomposites (mean molar mass, $\mathrm{Mw}$; KOH index, $I_{\mathrm{KOH}}$; density, $d$, and melting temperature, $\mathrm{Tm}$ )

\begin{tabular}{|c|c|c|c|c|c|c|c|}
\hline $\begin{array}{l}\text { Material } \\
\text { Type }\end{array}$ & Code & Nature & $\begin{array}{l}\text { Commercial } \\
\text { Name }\end{array}$ & $\begin{array}{c}\mathrm{Mw} \\
(\mathrm{g} / \mathrm{mol})\end{array}$ & $\begin{array}{c}I_{\mathrm{KOH}} \\
\left(\mathrm{mg}_{\mathrm{KOH}} / \mathrm{g}\right)\end{array}$ & $\begin{array}{c}d \\
\left(\mathrm{~g} / \mathrm{cm}^{3}\right)\end{array}$ & $\begin{array}{c}T m \\
\left({ }^{\circ} \mathrm{C}\right)\end{array}$ \\
\hline \multirow[t]{2}{*}{$\begin{array}{l}\text { Polymer } \\
\text { matrix }\end{array}$} & PA6 & Polyamide 6 & $\begin{array}{l}\text { Ultramid B4F } \\
\qquad(B A S F)\end{array}$ & 68000 & I & 1.13 & 219 \\
\hline & PE & High density polyethylene & $\begin{array}{c}\text { Eraclene ML74 } \\
\text { (Polimeri Europa) }\end{array}$ & 122400 & I & 0.951 & 130 \\
\hline \multirow[t]{4}{*}{$\begin{array}{l}\text { Interfacial } \\
\text { agents }\end{array}$} & hwMA9 & $\begin{array}{l}\text { High molar mass maleic } \\
\text { anhydride grafted } \\
\text { polyethylene }\end{array}$ & $\begin{array}{l}\text { Polybond } 3009 \\
\text { (Uniroyal) }\end{array}$ & 61571 & 9 & 0.95 & 127 \\
\hline & lwMA6 & $\begin{array}{l}\text { Low molar mass maleic } \\
\text { anhydride grafted } \\
\text { polyethylene }\end{array}$ & $\begin{array}{c}456624 \\
\text { (Sigma Aldrich) }\end{array}$ & 10400 & 6 & 0.92 & 107 \\
\hline & $1 w 0 X 16$ & $\begin{array}{l}\text { Low molar mass oxydized } \\
\text { polyethylene }\end{array}$ & $\begin{array}{l}\text { Licowax PED } 121 \\
107093(\text { Clariant })\end{array}$ & 10400 & $16-19$ & 0.97-0.99 & 113 \\
\hline & $\operatorname{mwOX16}$ & $\begin{array}{l}\text { Middle molar mass oxydized } \\
\text { polyethylene }\end{array}$ & AC316 (Honeywell) & 19650 & 16 & 0.95 & 116 \\
\hline \multirow[t]{2}{*}{ Clays } & MMT-OH & $\begin{array}{l}\text { Dihydroxy methyl tallow } \\
\text { ammonium modified } \\
\text { montmorillonite }\end{array}$ & $\begin{array}{l}\text { Nanofil } 804 \\
\text { (Süd Chemie) }\end{array}$ & I & I & 1.83 & I \\
\hline & $\begin{array}{l}\text { MMT- } \\
\text { Tallow }\end{array}$ & $\begin{array}{l}\text { Dimethyl ditallow } \\
\text { ammonium modified } \\
\text { montmorillonite }\end{array}$ & $\begin{array}{l}\text { Nanofil } 15 \\
\text { (Süd Chemie) }\end{array}$ & 1 & 1 & 1.83 & I \\
\hline
\end{tabular}

the parameters governing the filler dispersion state in PE based matrix and those allowing the increase of the barrier properties. At last, a step by step approach based on the control of the morphology and clay/matrix interfacial properties is proposed to optimize the gas barrier properties of PE based nanocomposites.

\section{EXPERIMENTAL}

\subsection{Materials}

The materials used in this study are presented in Table 1.

The polyamide 6 (PA6) was Ultramid B4F from $B A S F$ with an average molecular weight, $\mathrm{Mw}$, equal to 68000 g.mol ${ }^{-1}$.

The high density polyethylene (PE) was Eraclene ML74 from Polimeri Europa with an average molecular weight, Mw, equal to 122400 g.mol ${ }^{-1}$.

Four modified polyethylenes were used as interfacial agents to improve the interactions between the polymer and the clays in the PE based nanocomposites. These interfacial agents could be classified in two distinct families, maleic anhydride grafted polyethylenes on one hand and oxidized polyethylenes on the other hand. They were characterized by their average molar mass and their modification rate: $h w M A 9$ was a high molar mass maleic anhydride grafted polyethylene $\left(\mathrm{Mw}=61570 \mathrm{~g} \cdot \mathrm{mol}^{-1}\right)$ characterized by a $\mathrm{KOH}$ index of $9 \mathrm{mg}_{\mathrm{KOH}} \cdot \mathrm{g}^{-1}$. lwMA6 was a low molar mass maleic anhydride grafted polyethylene $\left(\mathrm{Mw}=10400 \mathrm{~g} \cdot \mathrm{mol}^{-1}\right)$ characterized by a $\mathrm{KOH}$ index of $6 \mathrm{mg}_{\mathrm{KOH}} \cdot \mathrm{g}^{-1}$. lwOX16 and $\mathrm{mwOX16}$ were two oxidized paraffins characterized by a $\mathrm{KOH}$ index of $16 \mathrm{mg}_{\mathrm{KOH}} \cdot \mathrm{g}^{-1}$. Their weight average molar mass was equal to 10400 g.mol ${ }^{-1}$ and 19650 g.mol ${ }^{-1}$, respectively.

The clays used in this work were organically modified clays provided by Süd Chemie. The quaternary ammonium used to modify the nanoclay was chosen as a function of the polymer matrix: dihydroxy methyl tallow quaternary ammonium for the PA6 matrix leading to MMT-OH montmorillonite and dimethyl ditallow quaternary ammonium for the PE matrix leading to MMT-Tallow montmorillonite, respectively. The organic surfactant weight content was $30.8 \mathrm{wt} \%$ for MMT-OH and $35.7 \mathrm{wt} \%$ for MMT-Tallow [48].

\subsection{Matrix and Nanocomposite Film Processing}

Compounded PA and PE nanocomposites were elaborated by melt intercalation on a twin screw co-rotating 
extruder, with a diameter $D=25 \mathrm{~mm}$, a length equivalent to $36 \times D$ and a feed rate of $1.3 \mathrm{~kg} . \mathrm{h}^{-1}$. The barrel temperature and the feed rate were fixed to $260^{\circ} \mathrm{C}$ and $100 \mathrm{rpm}$ for the PA based nanocomposites and to $200^{\circ} \mathrm{C}$ and $100 \mathrm{rpm}$ for the PE based nanocomposites, respectively. Polyamide pellets and OMMT were dried in a vacuum oven at $80^{\circ} \mathrm{C}$ for at least $12 \mathrm{~h}$ before melt blending to avoid the presence of water during melt process.

Reference matrices were prepared from pure PA, pure $\mathrm{PE}$ and $\mathrm{PE} /$ interfacial agent blends according to the same protocol as that used for the nanocomposites.

Reference and nanocomposite films were obtained by blow molding of the formulations with a Clextral E20T equipment. The extrusion temperature was fixed at $260^{\circ} \mathrm{C}$ for the PA based formulations and at $200^{\circ} \mathrm{C}$ for the PE based formulations. The screw speed was fixed at $80 \mathrm{rpm}$ and the blow up ratio was estimated to be equal to 2 .

\subsection{Nanocomposites Characterization}

Clay dispersion was analyzed at two scales:

- by Transmission Electron Microscopy (TEM) to get information up to a few micron square area and,

- by wide angle X-Ray Diffraction (XRD) to get $d$-spacing, $d_{001}$, between the platelets.

For transmission electron microscopy observations, the samples were embedded in an epoxy resin. Sections with a thickness of $60 \mathrm{~nm}$ were prepared by cutting the samples with an ultramicrotome Reichert $\mathrm{S}$ at a temperature of $-130^{\circ} \mathrm{C}$. The TEM observations were performed on a JEOL-200CX microscope operating at $200 \mathrm{kV}$. A quantitative analysis of the TEM images was performed according to the protocol described in a previous study [21]. The diffraction patterns were obtained at room temperature in the range of $2 \theta$ between 1 and $10^{\circ}$ by step of $0.02^{\circ}$ using a $\mathrm{Cu}$ tube and a Siemens D500 diffractometer where the $k \beta$ line was removed with a nickel filter. The films were deposited on neutral monosubstrates with a thin transfer adhesive with low scattering response.

The matrix crystallinity was determined by differential scanning calorimetry using a DSC2020 apparatus from $T A$ instruments. The polymer melting enthalpy $(\Delta H$ :

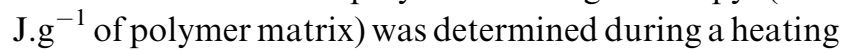
scan performed at $10 \mathrm{~K} \cdot \mathrm{min}^{-1}$ on a $10 \mathrm{mg}$ sample. The crystallinity values were calculated from the ratio between $\Delta H$ and $\Delta H f_{\infty} . \Delta H f_{\infty}$ value was taken equal to $290 \mathrm{J.g}^{-1}$ for the polyethylene based materials [49] and $190 \mathrm{~J}^{-g^{-1}}$ for the polyamide based formulations [50].

The permeability coefficients were determined for helium, hydrogen and oxygen from the gas flux value measured through the sample at the steady state. The measurements were performed at $20^{\circ} \mathrm{C}$ under a pressure gradient of 3 bar, according to an already described procedure [8]. The permeability coefficient was expressed in barrer units $\left(1\right.$ barrer $=10^{-10} \mathrm{~cm}^{3}$ STP. $\mathrm{cm} \cdot \mathrm{cm}^{-2} \cdot \mathrm{s}^{-1} \cdot \mathrm{cm}_{\mathrm{Hg}}{ }^{-1}$ $=7.5 \times 10^{-18} \mathrm{Nm}^{3} \cdot \mathrm{m} \cdot \mathrm{m}^{-2} \cdot \mathrm{s}^{-1} \cdot \mathrm{Pa}^{-1}=3.348 \times 10^{-16}$ mol.m. $\left.\mathrm{m}^{-2} \cdot \mathrm{s}^{-1} \cdot \mathrm{Pa}^{-1}\right)$.

\section{RESULTS AND DISCUSSION}

\subsection{Binary Systems: PA/MMT-OH and PE/MMT-Tallow}

The binary systems have been prepared with $5 \mathrm{wt} \%$ organoclay.

The X-ray diffraction curves of the organo-modified montmorillonites and of the respective PA or PE nanocomposites are presented in Figure 1.

The strong diffraction peak observed at $2 \theta=5^{\circ}$ for MMT-OH, corresponding to a basal spacing, $d_{001}$, of $18 \AA$ is no more observed on the PA/MMT-OH diffraction pattern. The silicate platelets seem then to be well exfoliated in the PA matrix.

On the contrary, the diffraction peak characteristic of the $d_{001}$ value of MMT-Tallow $\left(2 \theta=3.8^{\circ}\right.$ and $\left.d_{001}=28 \AA\right)$ is still evidenced on the XRD curve of PE/MMTTallow. A microcomposite seems to be obtained in this case despite the use of an organo-modified, less polar clay.

TEM micrographs presented in Figure 2 confirm the conclusions drawn from XRD analyses. Indeed, the clay particles are well exfoliated and homogeneously dispersed in the PA matrix whereas they form large and dense aggregates in the PE matrix. In both cases, the platelets are lying in the plane of the films. A statistical analysis of ten TEM images has allowed to determine the mean filler aspect ratio, $\alpha$, for each system and the volume fraction related to the dispersed objects. $\alpha$ is equal to 20 and 2.5 and $\phi$ is equal to 0.0277 and 0.0285 for PA/MMT-OH and PE/MMT-Tallow, respectively.

The impact of nanoclay introduction has been studied on the matrix crystalline morphology as well as on the gas barrier properties. The results reported in Table 2 show at first that the crystallinity degree values and the gas permeability coefficients determined on the neat matrices are in good agreement with those commonly reported in the literature [17, 21, 33]. PA matrix is characterized by enhanced gas barrier properties despite its lower crystallinity rate. This feature is related to the higher cohesive energy density developed in the amorphous phase for this polar polymer. The introduction of clays does not modify the crystallinity degree of 

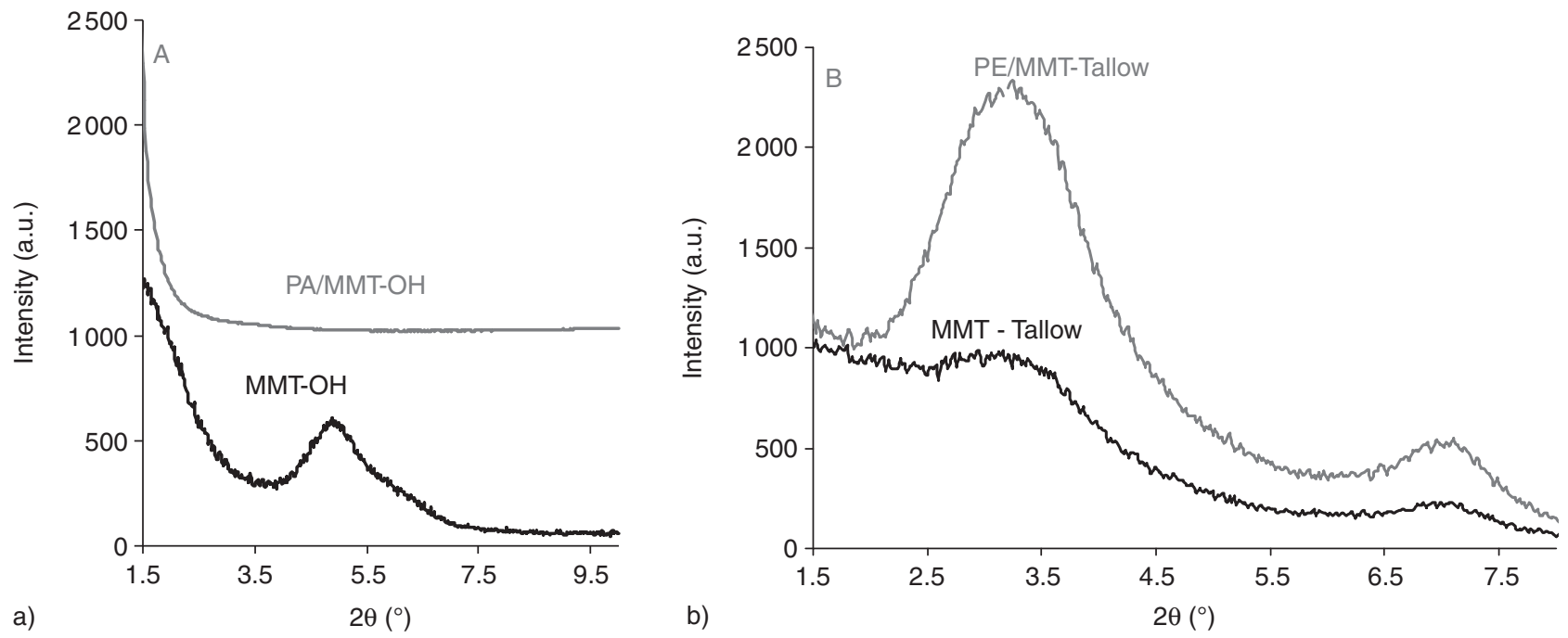

Figure 1

X-ray diffraction patterns of the organo-modified montmorillonites and their respective a) PA and b) PE nanocomposite films.

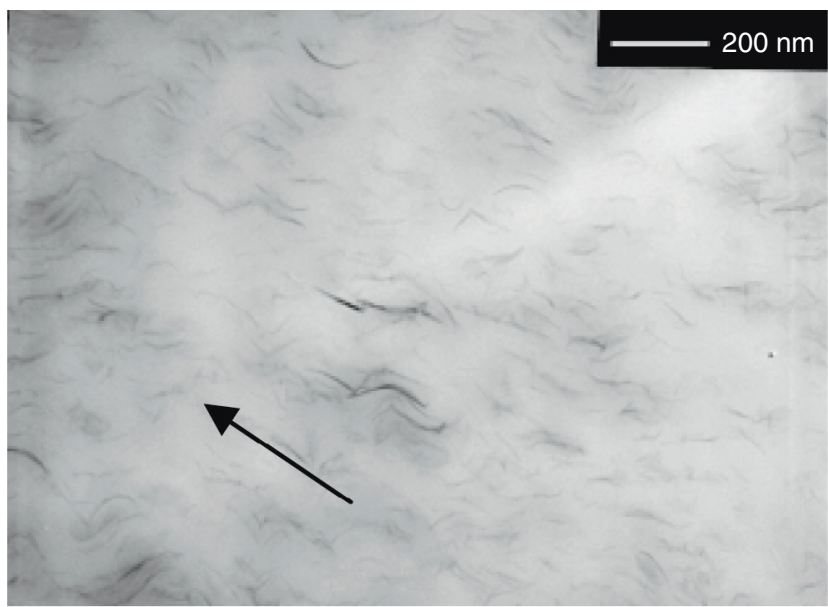

a)

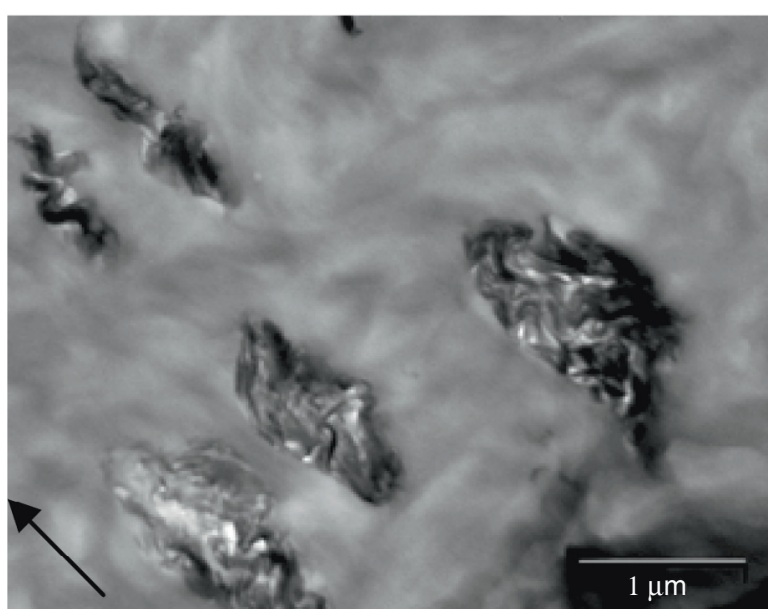

b)

Figure 2

TEM micrographs of a) PA/MMT-OH and b) PE/MMT-Tallow. The arrow is oriented parallel to the film surface.

TABLE 2

Crystallinity degree $(X c)$, experimental values of the gas permeability coefficients of the neat PA and PE matrices and their respective nanocomposites $\left(P_{\text {exp }}\right)$ and calculated values of the permeability coefficients deduced from Nielsen law $\left(P_{n c}\right)$ for the composites

\begin{tabular}{l|c|c|c|c|c|c|c}
\hline & $X c(\%)$ & $\begin{array}{c}P_{\text {exp }} \mathrm{H}_{2} \\
\text { (barrer) }\end{array}$ & $\begin{array}{c}P_{n c} \mathrm{H}_{2} \\
\text { (barrer) }\end{array}$ & $\begin{array}{c}P_{\text {exp }} \mathrm{He} \\
\text { (barrer) }\end{array}$ & $\begin{array}{c}P_{n c} \mathrm{He} \\
\text { (barrer) }\end{array}$ & $\begin{array}{c}P_{\text {exp }} \mathrm{CO}_{2} \\
\text { (barrer) }\end{array}$ & $\begin{array}{c}\mathrm{P}_{\mathrm{nc}} \mathrm{CO}_{2} \\
(\text { barrer) }\end{array}$ \\
\hline PA & 29.5 & 0.58 & $/$ & 0.87 & $/$ & $\mathrm{n} . \mathrm{m}$. & $/$ \\
\hline PA/MMT-OH & 29.6 & 0.43 & 0.44 & 0.64 & 0.66 & $\mathrm{n} . \mathrm{m}$. & $/$ \\
\hline PE & 66 & 3.42 & $/$ & 2.56 & $/$ & 4.27 & $/$ \\
\hline PE/MMT-Tallow & 66 & 3.50 & 3.21 & 2.69 & 2.40 & 4.20 & 4.00 \\
\hline
\end{tabular}


the polymer matrices but has different effects on their gas permeability coefficients (Tab. 2). A significant decrease of gas permeability is observed on PA/MMT-OH with respect to pure PA matrix whereas no significant variation of the gas permeability is evidenced on PE/MMT-Tallow in comparison with neat PE. The gas permeability decrease observed on PA nanocomposite is in good agreement with that calculated from Nielsen law [37] (Eq. l), considering the mean filler aspect ratio, $\alpha$, deduced from TEM analysis $(\alpha=20)$.

$$
P_{n c}=P_{m} \frac{1-\phi}{1+\frac{\alpha \phi}{2}}
$$

where $P_{n c}$ is the permeability of the nanocomposite, $P_{m}$ the permeability of the matrix, $\phi$ the volume fraction of the dispersed impermeable domains and $\alpha$ the mean aspect ratio of these domains.

According to this law, a small decrease of gas permeability should also be observed for PE/MMT-Tallow (Tab. 2). The non modification of the experimental permeability coefficients after nanoclay adding suggests a lack of interactions between the clays and the polymer matrix in this system. That is why interfacial agents have been introduced in the PE/MMT-Tallow formulation.

\subsection{Ternary Systems Based on PE Matrix: Influence of Different Interfacial Agents on the Nanocomposite Morphology and Properties}

Two kinds of interfacial agents consisting in modified polyethylenes have been introduced in the
PE/MMT-Tallow formulation, with the aim to evidence the role of their modification type and rate as well as the role of their molar mass on the nanocomposite morphology and gas barrier properties. Maleic anhydride grafted polyolefins are the most common interfacial agents used in polyolefin based nanocomposites. The interest of oxidized paraffins for gas barrier properties was first demonstrated by our team few years ago $[29,30]$ and then confirmed by other groups [31].

For this study, nanocomposites with the following weight composition $75 \mathrm{wt} \% \mathrm{PE} / 20 \mathrm{wt} \%$ interfacial agent $/ 5 \mathrm{wt} \%$ MMT-Tallow were prepared by melt blending according to the protocol described in the experimental part. Indeed, some studies reported that, the maleic anhydride grafted polyolefin/clay weight ratio should be at least equal to 4 to achieve an optimised clay dispersion state [51]. The respective matrices were also prepared from the same melt blending conditions and characterized. The data reported in Table 3 show that the matrices display slightly higher barrier properties in comparison with neat PE despite their slightly lower crystallinity degree. This behaviour was assigned to the polar character of the compatibilizers. The crystallinity values of the composite films were determined from DSC analysis. Indeed, the polymer crystalline phase is considered to be an impermeable phase for gas transport. It was thus important to check that no significant modification of the matrix crystallinity occurred after addition of nanoclays to discuss the sole effects of the lamellar fillers. The values of the temperature at the maximum of the melting peak, Tm, and of the crystallinity degree, $X c$, determined from the $D S C$ thermograms are

TABLE 3

Influence of the interfacial agent on the matrix microstructure, on the clay dispersion state and on the gas permeability coefficients. $\mathrm{Tm}$ is the polymer matrix melting temperature, $X c$ its crystallinity degree, $d_{001}$ is the interplatelet distance, $P$ is the permeability coefficient

\begin{tabular}{|c|c|c|c|c|c|c|c|}
\hline & $\operatorname{Tm}\left({ }^{\circ} \mathrm{C}\right)$ & $X c(\%)$ & $d_{001}(\AA)$ & $P \mathrm{H}_{2}$ (barrer) & $P \mathrm{He}$ (barrer) & $\mathrm{PO}_{2}$ (barrer) & $\mathrm{PCO}_{2}$ (barrer) \\
\hline PE/hwMA9 & 128.5 & 62.6 & l & 2.79 & 1.99 & 0.87 & 3.49 \\
\hline PE/lwMA6 & 127.6 & 59.1 & 1 & 3.17 & 2.29 & 0.99 & 4.14 \\
\hline $\mathrm{PE} / \mathrm{lwOx} 16$ & 127.8 & 62.1 & 1 & 2.57 & 1.89 & 0.76 & 3.12 \\
\hline $\mathrm{PE} / \mathrm{mwOX} 16$ & & 63.3 & l & 2.48 & 1.84 & 0.74 & 3.05 \\
\hline $\begin{array}{l}\text { PE/hwMA9/ } \\
\text { MMT-Tallow }\end{array}$ & 128.6 & 62.5 & l & 2.66 & 1.92 & 0.82 & 3.4 \\
\hline $\begin{array}{l}\text { PE/lwMA6/ } \\
\text { MMT-Tallow }\end{array}$ & 127.5 & 58 & 32.7 & 2.67 & 1.90 & 0.83 & 3.55 \\
\hline $\begin{array}{l}\text { PE/lwOx16/ } \\
\text { MMT-Tallow }\end{array}$ & 127.8 & 60.5 & 34.3 & 1.91 & 1.44 & 0.58 & 2.27 \\
\hline $\begin{array}{l}\mathrm{PE} / \mathrm{mwOX} 16 / \\
\text { MMT-Tallow }\end{array}$ & 128.1 & 62.8 & 35.3 & 1.57 & 1.17 & 0.42 & 1.77 \\
\hline
\end{tabular}


reported in Table 3 for the matrices and associated nanocomposites. Tm and $X c$ values measured on the nanocomposites do not differ from those determined on the respective matrices, allowing us to assign the gas permeability variation to a sole clay effect.

The filler dispersion state has been investigated by TEM and XRD analysis. A TEM micrograph representative of each nanocomposite is presented in Figure 3. A significant improvement of the filler dispersion state is observed on the ternary systems with respect to the binary one (as shown by the comparison between Fig. 3 and Fig. 2b). Indeed the large and dense aggregates of platelets evidenced in the neat PE are no more observed in the ternary systems. Even if some filler tactoids remain in the ternary blends, they are much smaller than those observed in the binary blend. However, despite this general trend, some differences can be observed as a function of the interfacial agent nature and molar mass.
The nanocomposite film prepared with $h w M A 9$ clearly exhibits individualized inorganic sheets, whereas more numerous small stacks of platelets are observed with lwMA6. Large but highly swollen filler aggregates are mainly evidenced in the nanocomposites prepared from lwOX16 and $m w O X 16$. This qualitative analysis of the filler dispersion state is in agreement with the data drawn from the XRD spectra (Tab. 3). Indeed no well defined diffraction peak is observed in the $2 \theta$ range from 1.5 to $7.5^{\circ}$ for the nanocomposite based on hwMA9 making impossible the calculation of a $d_{001}$ value whereas the basal diffraction peak of the organoclay is shifted towards lower value of $2 \theta$ for the three other nanocomposites. The values of the filler $d$-spacing in these nanocomposites, deduced from the diffraction peak position, are reported in Table 3 . The $d_{001}$ value increases going from uncompatibilized PE matrix $\left(d_{001}=28 \AA\right)$ to $\mathrm{PE} / \mathrm{lwMA} 6, \mathrm{PE} / \mathrm{lwOx} 16$ and $\mathrm{PE} / \mathrm{mwOx} 16$ and it can no
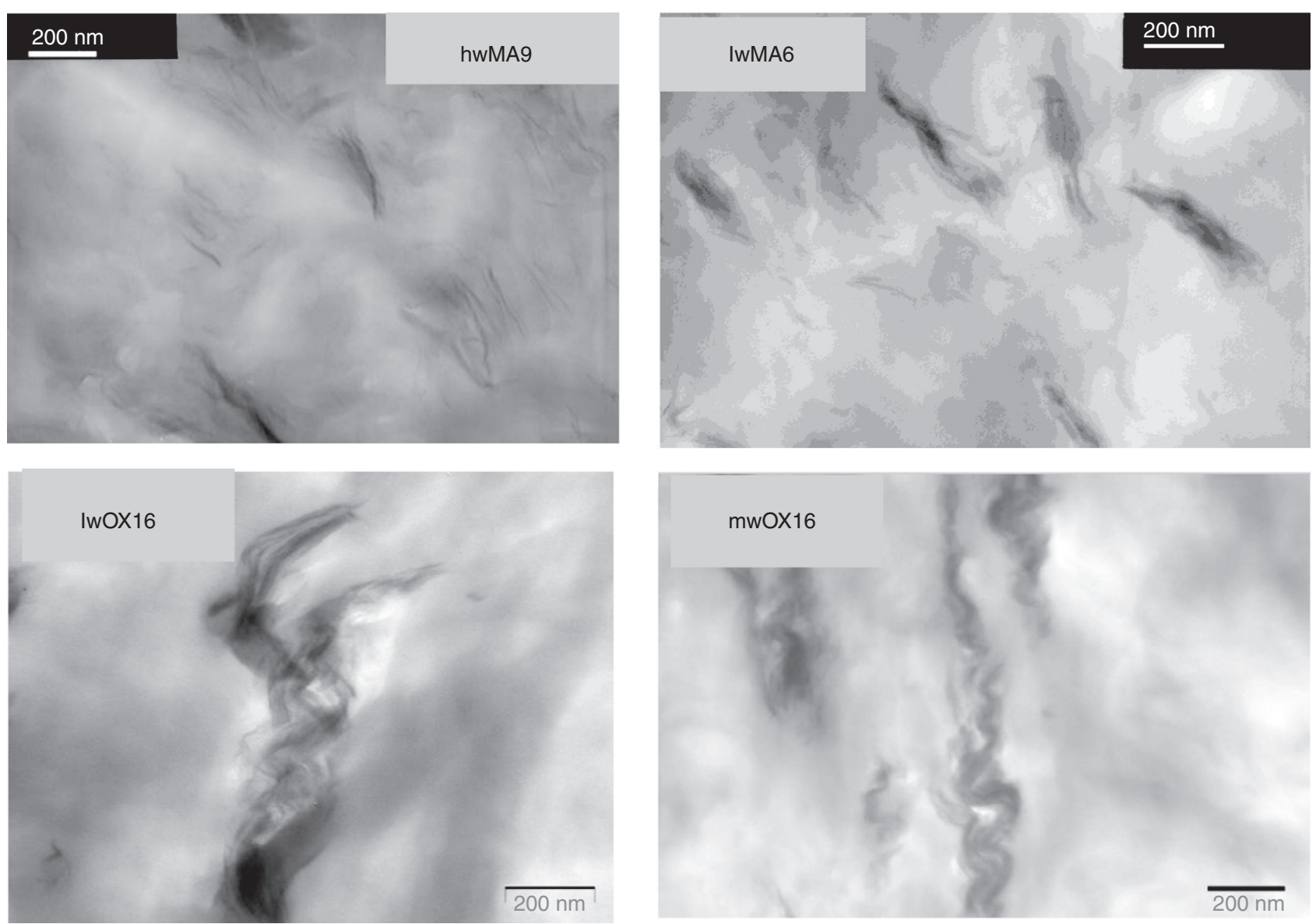

Figure 3

Influence of different interfacial agents on the clay dispersion state observed at the TEM scale. 


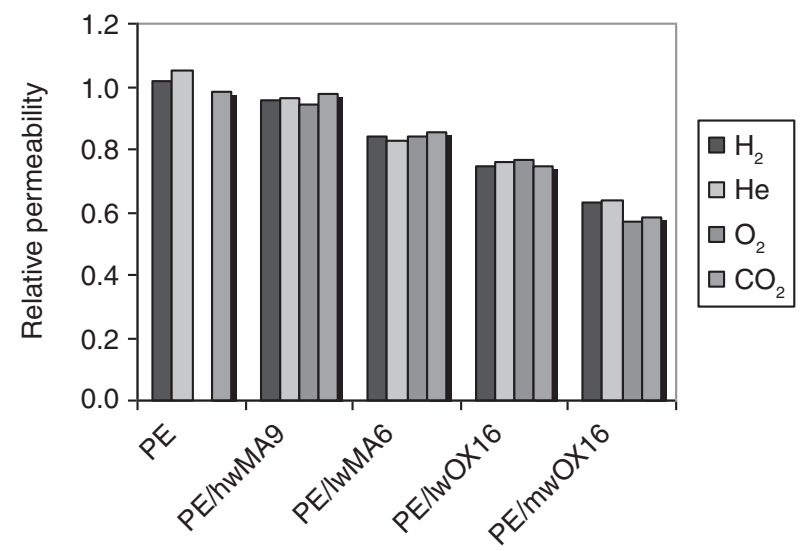

Figure 4

Relative permeability values measured for different gases on PE-based nanocomposite flms prepared with different interfacial agents.

more be determined in PE/hwMA9 due to the clay platelet exfoliation in this last matrix. According to these results, it seems that high clay delamination states can only be achieved with high molar mass compatibilizers, low or middle mass interfacial agents allowing only obtaining intercalated structures. Moreover, in these last systems, the higher the modification rate of the compatibilizer is, the more highly swollen clay aggregates are obtained.

The gas permeability coefficients have been determined on the nanocomposites and on their respective matrices. The permeability values have been reported in Table 3. The relative permeability, the ratio between the permeability of the nanocomposite to that of the respective matrix, can be calculated from these values. This parameter, reported in Figure 4 for each gas and nanocomposite, allows to discuss the impact of clay introduction within each compatibilized matrix. In this nanocomposite series, the highest improvement of barrier properties is not obtained for the exfoliated structures but for the intercalated structures. This surprising result can only be explained by considering that the gas diffusion rate at the filler/matrix interface is higher than the gas diffusion rate in the bulk matrix for PE/hwMA9/MMT-Tallow. Due to exfoliation, the amount of filler/matrix interfaces is important leading to a global increase of the gas permeability. This negative contribution of the filler/matrix interface does not take place in the three other systems, in which a more classical behaviour, e.g. a decrease of gas permeability, is observed. Moreover, it can be observed that the barrier properties enhancement is as more important as the interplatelet distance increases within the swollen clay aggregates. This trend is in agreement with the increase of the volume fraction of impermeable or at least very low permeable domains that are constituted by the highly swollen clay aggregates.

The main conclusion that can be drawn from this study is that the barrier properties can not always be directly related to the clay dispersion state and that the filler/matrix interface can also play a major role on gas transport properties. Furthermore, oxidized wax seems to be a particularly interesting interfacial agent for PE based nanocomposites. That is why the next part of the work was focussed on a detailed study of such systems.

\subsection{Ternary Systems Based on PE Matrix and IwOX16}

\subsubsection{Influence of the Interfacial Agent Content}

Certain studies have shown that, in the case of a maleic anhydride grafted polyolefins, a nanofiller/compatibilizer weight ratio of $1 / 4$ was optimal to obtain good functional properties [51]. The aim of this part is to study the influence of the rate of $l w O X 16$ on the barrier properties. The amount of MMT-Tallow is fixed to $5 \mathrm{wt} \%$. The rate of compatibilizer varies from 0 to $30 \mathrm{wt} \%$. Beyond, because of the low molar mass of $l w O X 16$, it was not possible any more to prepare films by extrusion blowing.

The clay dispersion state is not profoundly modified by addition of increasing amounts of $l w O X 16$. The XRD patterns of the nanocomposites display an intense peak centered on $2.6^{\circ}$ whatever is the rate of interfacial agent (Fig. 5). The morphology is then mainly composed by intercalated structures with a mean interplatelet distance of the order of $34 \AA$.

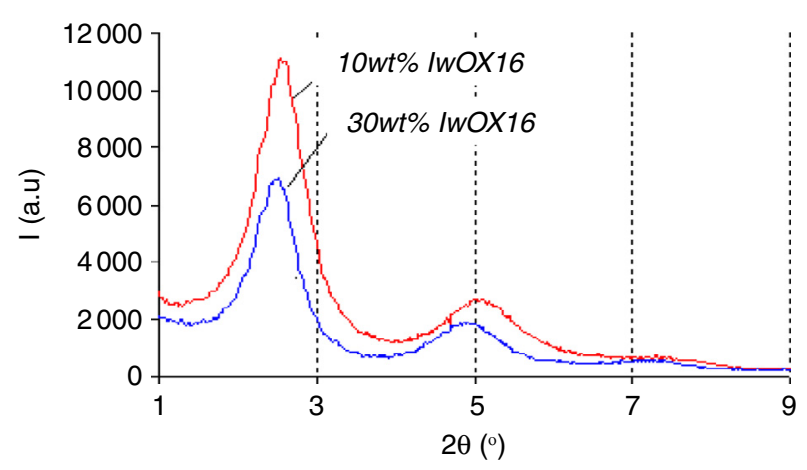

Figure 5

X-ray diffraction patterns of the nanocomposites as a function of the weight content of $l w O X 16$ interfacial agent. 


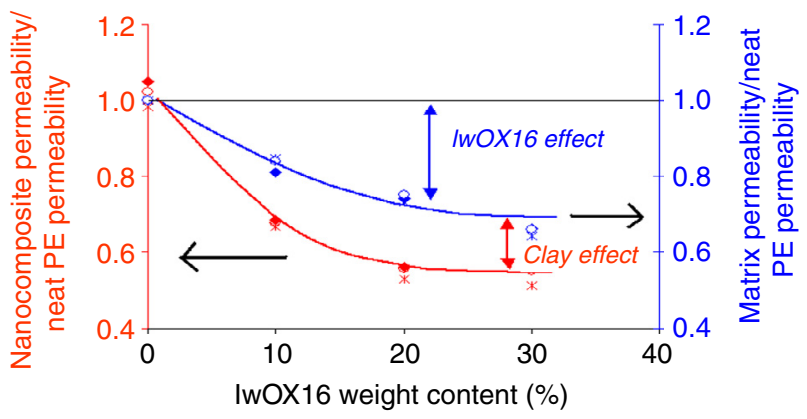

Figure 6

Influence of $l w O X 16$ weight amount on the nanocomposites and matrices permeability with respect to the permeability of neat PE for $(\bullet)$ helium, $(\bigcirc)$ hydrogen and $(*)$ carbon dioxide.

Whatever is the considered gas, the barrier properties of nanocomposites increase until the rate of $l w O X 16$ reaches $20 \mathrm{wt} \%$, then they stabilize (Fig. 6). This evolution can be explained in the light of the evolution of the relative permeability of the matrices. We can notice in Figure 6 that, the curves representative of the matrices and of the nanocomposites behaviour show the same trends. This means that, for the range of compatibilizer between 10 and $30 \mathrm{wt} \%$, filler loading has the same effect on the permeability. Moreover, the optimum oxidized wax to clay weight ratio can be drawn from this figure: it seems to be equal to 4 , as for maleic anhydride grafted polyethylene.

\subsubsection{Influence of the Nanoclay Content}

To study the effect of the nanoclay content, the compatibilizer weight amount has been fixed to $30 \%$ and the clay amount has been progressively increased to 7.5 , 10.6 and $16.2 \mathrm{wt} \%$, respectively. The choice of the compositions was made in order to achieve the best compromise considering the processability of the formulations in terms of extrusion blowing on one hand and the optimal compatibilizer to clay weight ratio on the other hand.

The TEM micrographs presented in Figure 7 show that the nanocomposite morphology is similar in all the range of considered clay amount with the presence of numerous swollen clay aggregates.

A quantitative analysis of the size of the dispersed domains has been performed from the detailed observation of at least 10 TEM micrographs for each sample. The results reported in Figure 8 show that the filler dispersion state is less optimised in high loaded systems. Indeed, the proportion of high size filler aggregates increases as the filler content increases within the matrix. However, the mean interplatelet distance determined by XRD analysis remains constant and equal to $34.5 \AA$, whatever the clay content. Moreover, increasing the clay content in the range from 0 to $16 \mathrm{wt} \%$ does not lead to modify the matrix crystallinity degree $(X c=63 \%)$.

The gas barrier properties are enhanced as the filler content increases (Fig. 9). The decrease of the gas transport properties is significant for clay content going from 0 to $7.5 \mathrm{wt} \%$. It is much more limited for clay content above $10 \mathrm{wt} \%$, due to the presence of numerous micrometric platelet aggregates characterized by a low aspect ratio. According to these results, it seemed then interesting to improve the global dispersion state of the fillers within $\mathrm{PE} / \mathrm{lw} O x 16$ based matrix that is why quaternary systems were investigated.

\subsection{Quaternary Systems Based on PE Matrix: Simultaneous Use of hwMA9 and IwOX16}

The previous study has shown that the oxidized paraffins could induce interesting filler/matrix interfacial properties for gas barrier application but could not allow obtaining clay delamination whereas $h w M A 9$ could lead to exfoliated structures but non optimized filler/matrix properties. Therefore, it was interesting to see if a synergism could be obtained by the simultaneous use of the two interfacial agents, $h w M A 9$ and $l w O X 16$. Two nanocomposites were prepared for $5 \mathrm{wt} \%$ MMT-Tallow, the first one containing $10 \mathrm{wt} \%$ of each interfacial agent and the second one $20 \mathrm{wt} \%$.

The XRD patterns reported in Figure 10 show that the structures of the nanocomposites based on $h w M A 9$ and $l w O X 16$ are similar to that one developed in the nanocomposite based on $l w O X 16$. Indeed an intense diffraction peak located at $2 \theta$ value around $2.9^{\circ}$ is observed for these nanocomposites, showing that an important part of the clays are intercalated. However, the TEM micrograph presented in Figure 11 allows modulating this conclusion as numerous individual platelets are observed in addition to swollen clay aggregates. The clay dispersion seems then to be improved in $\mathrm{PE} / 20 \%$ hwMA9 $+20 \% \quad l w O X 16 /$ MMT-Tallow (Fig. 11) in comparison with $\mathrm{PE} / 20 \%$ lwOX16/MMTTallow (Fig. 3).

The gas permeability coefficients of the different nanocomposites are reported in Figure 12. A small improvement of the gas barrier properties is observed by introducing $h w M A 9$ compatibilizer in addition to lw $O X 16$ in the system and by increasing the respective amount of each compatibilizer. 

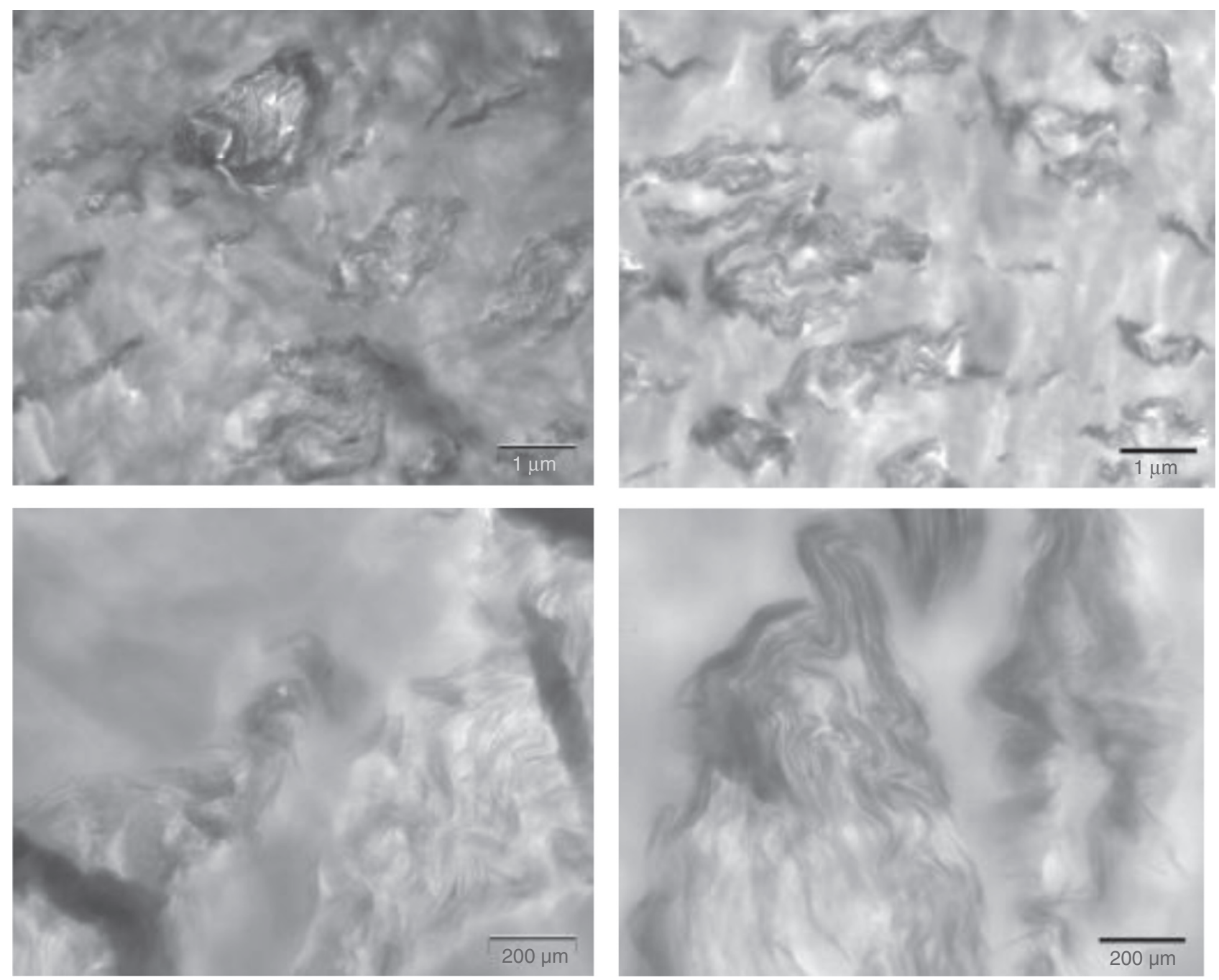

Figure 7

TEM micrographs representative of PE/lwOX16/MMT-Tallow for $30 \mathrm{wt} \%$ compatibilizer and $10.6 \mathrm{wt} \%$ (left side) and $16.2 \mathrm{wt} \%$ (right side) MMT-Tallow.

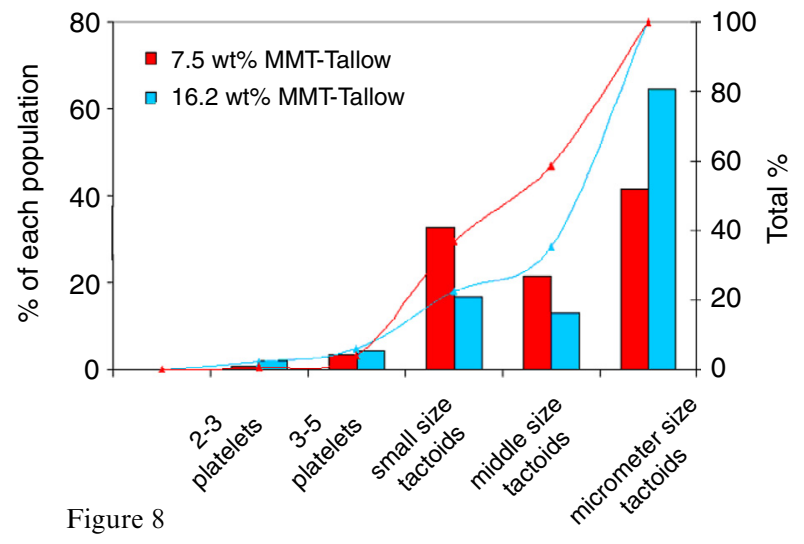

Quantitative analysis of the nanoclay dispersion within the nanocomposites based on $\mathrm{PE} / 30 \mathrm{wt} \%$ lwOX16 matrix.

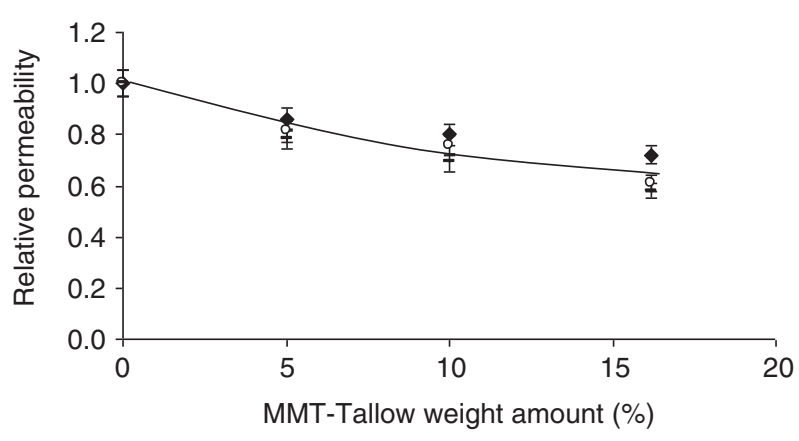

Figure 9

Influence of the clay content on the permeability of the nanocomposites based on $30 \mathrm{wt} \%$ oxidized wax for helium, $(\bigcirc)$ hydrogen and (-) carbon dioxide. 


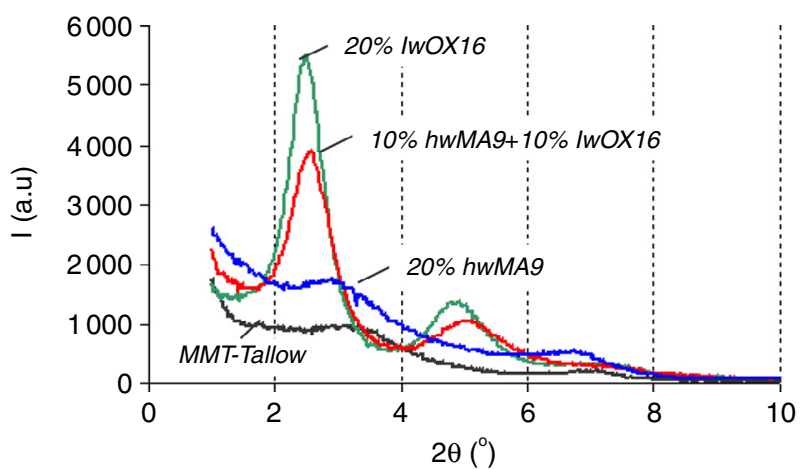

Figure 10

XRD patterns of the MMT-Tallow organoclay and of the PE nanocomposites based on $l w O X 16, h w M A 9$ and a ( $h w M A 9 /$ lwOX16) blend.

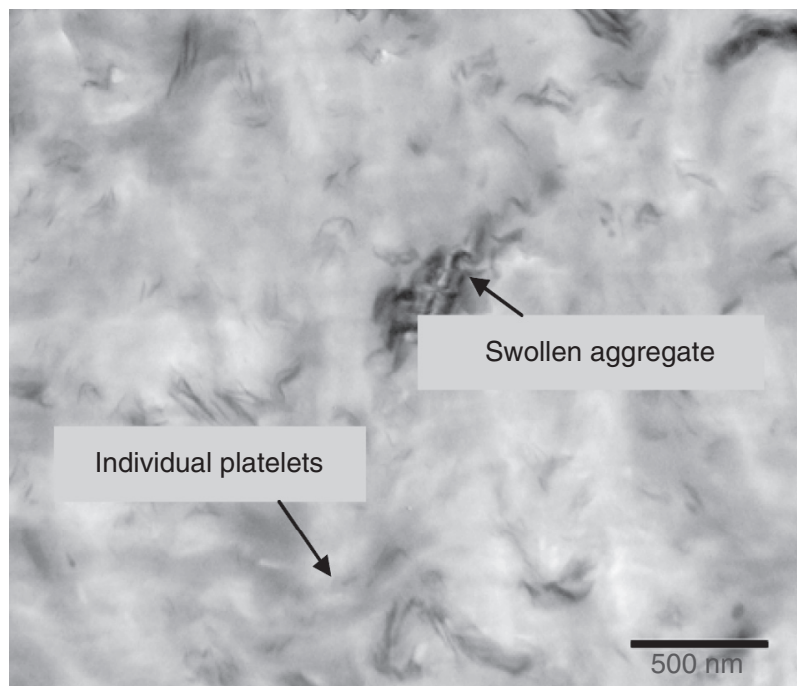

Figure 11

TEM micrograph of the PE nanocomposite based on $20 \mathrm{wt} \%$ $h w M A 9$ and $20 \mathrm{wt} \% l w O X 16$ as interfacial agent.

\section{CONCLUSION}

The comparative study of the binary PA/clay and $\mathrm{PE} /$ clay systems performed at $5 \mathrm{wt} \%$ of clays has shown that, despite an adjusted clay modification, the use of a polar matrix as clay dispersion medium was more favourable to reach clay exfoliation as well as to create strong enough clay/matrix interactions. As a result, a significant improvement of the gas barrier properties was observed in the PA/clay nanocomposite whereas no modification of these properties was evidenced in

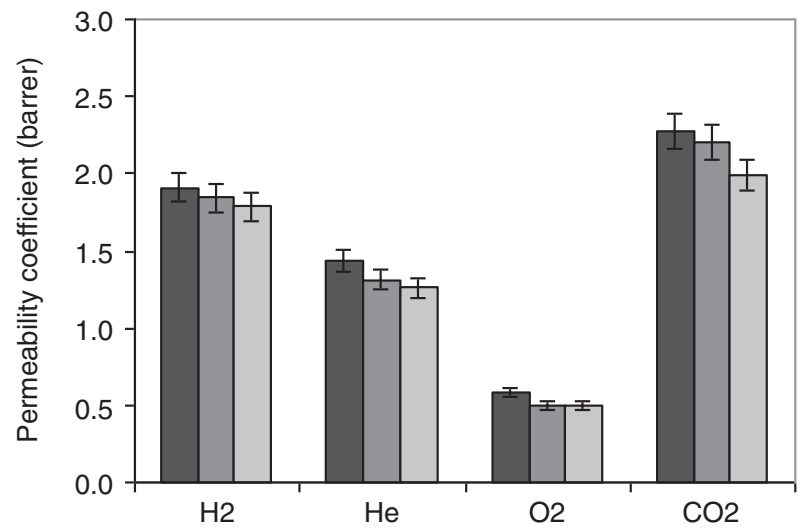

Figure 12

Permeability coefficients of the nanocomposites based on $5 \mathrm{wt} \%$ MMT-Tallow and ( $\square$ ) $20 \mathrm{wt} \%$ lwOX16, ( $\square$ ) $10 \mathrm{wt} \% l w O X 16+10 \mathrm{wt} \% h w M A 9$ and $(\square) 20 \mathrm{wt} \%$ $l w O X 16+20 \mathrm{wt} \% h w M A 9$ as interfacial agent within the PE matrix.

the PE based system. The gas permeability decrease was governed in the PA system by a tortuosity effect which was directly related to the clay dispersion state.

Addition of modified polyolefins was used as a mean to enhance the clay dispersion state within PE matrix. For each type of compatibilizer studied in this work, oxidized polyolefin type or maleic anhydride grafted polyolefin type, the optimum compatibilizer to clay weight ratio was found to be equal to 4 . However, the clay dispersion state could be very different as a function of the systems. It greatly depended, in fact, on the mean molar mass of the compatibilizer which defined the viscosity level of the dispersion medium, a high viscosity leading to enhanced clay dispersion. Exfoliated clays were then mainly obtained by using high molar mass maleic anhydride grafted polyethylene whereas swollen clay aggregates were observed with oxidized polyethylene of low or middle molar mass. In the compatibilized PE systems, the enhancement of the barrier properties subsequent to clay introduction was not directly related to the clay dispersion state since the clay/matrix interface played also a significant role. The interfacial properties seemed to greatly depend on the polarity of the compatibilizers. As a result, the clay/matrix interfaces brought a negative contribution to the reinforcement of the gas barrier properties in the system based on the high molar mass maleic anhydride grafted polyethylene due to the relatively low polarity of the compatibilizer whereas they allowed achieving a significant gas barrier improvement in the systems based on oxidized waxes, which were characterized by a higher value of the $\mathrm{KOH}$ index. 
Increasing the clay content to $10 \mathrm{wt} \%$ in this system did not drastically modify the clay dispersion state and allowed dividing the gas permeability by a factor 2 in comparison with neat PE. Higher filler loadings became detrimental to the filler dispersion state and did not bring further increase of the gas barrier properties. The simultaneous use of oxidized wax and maleic anhydride grafted polyethylene as compatibilizer was also investigated. The coexistence of exfoliated clays and swollen clay aggregates was evidenced in these systems and a small additional increase of the gas barrier properties in comparison with the system based on lonely oxidized wax was achieved. Thus interesting reinforcement of gas barrier properties could be achieved in a PE matrix by an appropriate choice of the compatibilizer rate, type and/ or compatibilizer combination, in addition to the adjustement of the organoclay content, keeping in mind that in these systems, the gas barrier properties did not result only from the clay dispersion state but also from the clay/matrix interfacial properties.

\section{REFERENCES}

1 Garmabi H., Demarquette N.R., Kamal M.R. (1998) Effect of temperature and compatibilizer on interfacial tension of PE/PA-6 and PP/EVOH, Int. Polym. Process. 13, 1833-1911.

2 Yeh J.T., Shih W.H., Huang S.S. (2002) Paint solvent permeation resistance of polyethylene, polyethylene/ polyamide and polyethylene/modified polyamide bottles, Macromol. Mater. Eng. 287, 23-30.

3 Correa C.A., Carvalho C.L., Bezzan A.L., Razzino C.A., Hage E. (2006) Structure property relationships in PA6 and PP copolymers blended by single and twin screw extrusion, Int. Polym. Proc. 21, 5, 440-448.

4 Dencheva N., Nunes T., Oliveira A.J., Denchev Z. (2005) Microfibrillar composites based on polyamide/polyethylene blends. 1. Structure investigations in oriented and isotropic polyamide 6, Polymer 46, 3, 887-901.

5 Holsti-Miettinen R.M., Perttiä K.P., Seppälä J.V., Heino M.T. (1995) Oxygen barrier properties of polypropylene/ polyamide 6 blends, J. Appl. Polym. Sci. 58, 1551-1560.

6 Eceolaza S., Iriarte M., Uriarte C., Etxeberria A. (2009) Barrier property enhancement of polyamide 6 by blending with a polyhydroxyamino-ether resin, J. Polym. Sci. B: Polym. Phys. 47, 1625-1634.

7 Guerrica-Echevarria G., Eguiazabal J.I., Nazabal J. (2003) Water sorption in polyamide 6/poly(amino-ether) blends. II. Mechanical behaviour, J. Macromol. Sci. Pure Appl. Chem. 40, 7, 705-714.

8 Lafitte G., Espuche E., Gérard J.F. (2011) Polyamide 11/ Poly(Hydroxy Amino Ether) Blends: Influence of the blend composition and morphology on the barrier and mechanical properties, Eur. Polym. J. 47, 10, 1994-2002.
9 Wang B.B., Hao L.X., Wang W., Hu G.S. (2010) One step compatibilization of polyamide $6 /$ poly(ethylene-1-octene) blends with maleic anhydride and peroxide, J. Polym. Res. 17, 6, 821-826.

10 Jeziorska R. (2005) Reactive compatibilization of polyester elastomer/polyamide 6 blends with oxazoline functionalized low-density polyethylene, Polimery 50, 4, 291-297.

11 Monticciolo A., Cassagnau P., Michel A. (1998) Fibrillar morphology development of PE/PBT blends: rheology and solvent permeability, Polym. Eng. Sci. 38, 1, 1882-1888.

12 Sarkissova M., Harrats C., Groeninckx G., Thomas S. (2004) Design and characterisation of microfibrillar reinforced composite materials based on PET/PA12 blends, Composites: Part A 35, 489-499.

13 Evstatiev M., Schultz J.M., Fakirov S., Friedrich K. (2001) In situ fibrillar reinforced PET/PA-6/Pa-66 blend, Polym. Eng. Sci. 41, 2, 192-204.

14 Sun L., Boo W.J., Sue H., Clearfield A. (2007) Preparation of alpha-zirconium phosphate nanoplatelets whit wide variations in aspect ratios, New J. Chem. 31, 39-43.

15 Xu B., Zheng Q., Song Y., Shangguan Y. (2006) Calculating barrier properties of polymer/clay nanocomposites: Effects of clay layers, Polymer 47, 2904-2910.

16 Yano K., Usuki A., Okada A. (1997) Synthesis and properties of polyimide-clay hybrid films, J. Polym. Sci. A: Polym. Chem. 35, 2493-2498.

17 Murase S., Inoue A., Miyashita Y., Kimura N., Nishio Y. (2002) Structural Characteristics and Moisture Sorption Behavior of Nylon6/Clay Hybrid Films, J. Polym. Sci. B: Polym. Phys. 40, 479-487.

18 Deguchi R., Nishio T., Okada A. (1993) Process for preparing a polyamide composite material, US Patent 5248720.

19 Hasegawa N., Okamoto H., Kato M., Usuki A., Sato N. (2003) Nylon6/Na-montmorillonite nanocomposites prepared by compounding nylon 6 with Na-montmorillonite slurry, Polymer 44, 2933-2937.

20 Leaversuch R. (2001) Nanocomposites broaden roles in automotive, barrier packaging, Plastics Technol. 47, 10-19.

21 Picard E., Vermogen A., Gérard J.F., Espuche E. (2007) Barrier properties of nylon 6-montmorillonite nanocomposite membranes prepared by melt blending: influence of the clay content and dispersion state. Consequences on modelling, J. Membr. Sci. 292, 133-144.

22 Alexandre B., Colasse L., Langevin D., Médéric T., Aubry T., Chappey C., Marais S. (2010) Transport mechanisms of small molecules through polyamide 12 /montmorillonite nanocomposites, J. Phys. Chem. B 114, 8827-8837.

23 Picard E., Gérard J.F., Espuche E. (2008) Water transport properties of polyamide 6 based nanocomposites prepared by melt blending: on the importance of the clay dispersion state on the water transport properties at high water activity, J. Membr. Sci. 313, 1-2, 284-295.

24 Alix S., Follain N., Tenn N., Alexandre B., Bourbigot S., Soulestin J., Marais S. (2012) Effect of highly exfoliated and oriented organoclays on the barrier properties of polyamide 6 based nanocomposites, J. Phys. Chem. Chem. C 116, 8, 4937-4947.

25 Zulfiqar S., Ishaq M., Sarwar M.I. (2008) Effect of surface modification of montmorillonite on the properties of aromatic polyamide/clay nanocomposites, Surf. Interface Anal. 40, 8, 1195-1201. 
26 Carvalho J.W.C., Sarantopoulos C., Innocentini-Mei L.H. (2010) Nanocomposites-based polyolefins as alternative to improve barrier properties, J. Appl. Polym. Sci. 118, 3695-3700.

27 Hong S.I., Rhim J.W. (2012) Preparation and properties of melt-intercalated linear low density polyethylene/Clay nanocomposite films prepared by blow extrusion, Food Sci. Technol. 48, 1, 43-51.

28 Waché R. (2004) Formulation et caractérisation de polyéthylènes charges avec des argyles. Propriétés barrière des nanocomposites obtenus, PhD Thesis, Université de Bretagne Occidentale, France.

29 Jacquelot E., Espuche E., Gérard J.F., Duchet J., Mazabraud P. (2006) Morphology and gas barrier properties of polyethylene based nanocomposites, J. Polym. Sci. B: Polym. Phys. 44, 431-440.

30 Picard E., Vermogen A., Gérard J.F., Espuche E. (2008) Influence of the compatibilizer polarity and molar mass on the morphology and the gas barrier properties of polyethylene/clay nanocomposites, J. Polym. Sci. B: Polym. Phys. 46, 23, 2593-2604.

31 Durmus A., Woo M., Kasgoz A., Macosko C.W., Tsapatsis M. (2007) Intercalated linear low density polyetrhylene (LLDPE)/clay nanocomposites prepared with oxidized polyethylene as new type compatibiizer: structural, mechanical and barrier properties, Eur. Polym. J. 43, 3737-3749.

32 Kato M., Okamoto H., Hasegawa N., Tsukigase A., Usuki A. (2003) Preparation and properties of polyethylene-clay hybrids, Polym. Eng. Sci. 43, 1312-1316.

33 Rupp J.E.P. (2004) Polyethylene-layered silicate nanocomposites, PhD Thesis, Zürich, Switzerland.

34 Sanchez Valdes S., Lopez Quintanilla M.L., Ramirez Vargas E., Medellin Rodriguez F.J., Gutierrez Rodriguez J.M. (2006) Effect of ionomeric compatibilizer on clay dispersion in polyethylene/clay nanocomposites, Macromol. Mater. Eng. 291, 128-136.

35 Shah R.K., Krishnaswamy R.K., Takahashi S., Paul D.R. (2006) Blown films of nanocomposites prepared from ow density polyethylene and a sodium ionomer of poly (ethylene-co-methacrylic acid), Polymer 47, 6187-6201.

36 Osman M.A., Atallah A. (2004) High-density polyethylene micro and nanocomposite: effect of particle shape, size and surface treatment on polymer cristallinity and gas permeability, Macromol. Rapid Comm. 25, 1540-1544.

37 Nielsen L.E. (1967) Models for the permeability of filled polymer systems, J. Macromol. Sci. Chem. A 1, 929-942.

38 Gusev A.A., Lusti H.R. (2001) Rational Design of nanocomposites for barrier applications, Adv. Mater. 13-21, 1641-1643.

39 Fredrickson G.H., Bicerano J. (1999) Barrier properties of oriented disk composites, J. Chem. Phys. 110-4, 2181-2188.
40 Lape N.K., Nuxoll E.N., Cussler E.L. (2004) Polydisperse flakes in barrier films, J. Membr. Sci. 236, 29-37.

41 Bharadwaj R.K. (2001) Modeling the barrier properties of polymer-layered silicate nanocomposite, Macromolecules 34, 9189-9192.

42 Yang C., Smyrl W.H., Cussler E.L. (2004) Flake alignment in composite coatings, J. Membr. Sci. 231, 1-12.

43 Gain O., Espuche E., Pollet E., Alexandre M., Dubois Ph (2005) Gas barrier properties of poly ( $\varepsilon$-caprolactone)/clay nanocomposites: influence of the morphology and polymer/clay interactions, J. Polym. Sci. B Polym. Phys. 43, 205-214.

44 Miltner H.E., Assche G.V., Pozsgay A., Pukansky B., Van Mele B. (2006) Restricted chain segment mobility in poly (amide) 6/clay nanocomposites evidenced by quasi-isothermal crystallization, Polymer 47, 826-835.

45 Adame D., Beall G.W. (2009) Direct measurement of the constrained polymer region in polyamide/clay nanocomposites and the implications for gas diffusion, Appl. Clay Sci. 42, 545-552.

46 Sabard M., Gouanvé F., Espuche E., Fulchiron R., Seytre G., Trouillet-fonti L., Fillot L.-A. (2012) Influence of film processing conditions on the morphology of polyamide 6 : consequences on water and ethanol sorption properties, J. Membr. Sci. 415-416, 670-680.

47 Beall G.W. (2000) New conceptual model for interpreting nanocomposite behaviour, Pinnavaia T.J., Beall G.W. (Des.), Polymer-clay nanocomposites, Wiley, New York, pp. 267-279.

48 Picard E., Gauthier H., Gérard J.F., Espuche E. (2007) Influence of the interlayer cations on the surface characteristics of montmorillonites. Consequences on the morphology and gas barrier properties of polyethylene/ montmorillonites nanocomposites, J. Colloid Interface Sci. 307, 364-376.

49 Wunderlich B. (1973) A Subsidiary of Harcourt Brace Jovanovich Publishers, Chap IV The defect crystal, in Macromolecular Physics, Vol I Crystal structure, morphology, defects, Academic Press, New York, London, pp. 380-511.

50 Liu L., Qi Z., Zhu X. (1999) Studies on Nylon 6/Clay Nanocomposites by Melt-Intercalation Process, J. Appl. Polym. Sci. 71, 1133-1138.

51 Boucard S. (2004) Développement de formulations polyoléfines/silicates lamellaires : contrôle de la nanostructuration par la gestion des interactions physico-chimiques et le procédé de mise en œuvre dans le fondu, PhD Thesis, INSA de Lyon, France.

Manuscript accepted in April 2013

Published online in December 2013

Cite this article as: E. Picard, J.-F. Gérard and E. Espuche (2015). Reinforcement of the Gas Barrier Properties of Polyethylene and Polyamide Through the Nanocomposite Approach: Key Factors and Limitations, Oil Gas Sci. Technol 70, 2, $237-249$. 